\title{
Prokinetics in the Management of Functional Gastrointestinal Disorders
}

\author{
Eamonn M M Quigley \\ Division of Gastroenterology and Hepatology, Department of Medicine, Houston Methodist Hospital, Houston, Texas, USA
}

A variety of common and some not common gastrointestinal syndromes are thought to be based on impaired gut motility. For some, the role of motility is well defined, for others and the functional gastrointestinal disorders, in particular, the role of hypo- or dysmotility remains unclear. Over the years pharmacological and physiological laboratories have developed drugs which stimulate gut motility; many have been evaluated in motility and functional disorders with what can best be described as mixed results. Lack of receptor specificity and resultant expected and unexpected adverse events have led to the demise of some of these agents. Newer, more selective agents offer promise but the heterogeneity of the clinical disorders they target continues to pose a formidable challenge to drug development in this area.

(J Neurogastroenterol Motil 2015;21:330-336)

Key Words

Constipation; Dyspepsia; Gastroparesis; Intestinal pseudo-obstruction; Irritable bowel syndrome

\section{Introduction}

The term prokinetic means simply to promote movement and, in the context of the gastrointestinal tract, was introduced to refer to a class of drugs that promoted gastrointestinal motility and, thereby, transit. This stimulatory effect was considered clinically relevant to the management of disorders characterized by impaired motility, such as gastro-esophageal reflux (in some instances), gastroparesis, intestinal pseudo-obstruction, and colonic inertia. However, as the complexity of symptom pathogenesis came to be understood and as the multifactorial nature of the more functional gastrointestinal disorders came to light, such a simplistic concept (stimulating motor activity) began to appear inadequate to address the contributions to symptoms of such factors as dysmotility, visceral hypersensitivity and altered visceral tone, as well as changes in compliance and accommodation. Hypomotility, the ideal target for a prokinetic, was unlikely to be relevant to all but a few rare disorders. Accordingly the field of study came to be renamed neurogastroenterology or, as in the case of ANMA, neurogastroenteology and motility. Newer concepts such as enteric neuro-modulation emerged and agents whose primary target was not motility but rather visceral sensation, for example, emerged. Also, with the emergence of new ideas relating to the pathophysiology of such common disorders as irritable bowel syndrome (IBS), a whole new set of therapeutic targets came in to range; from the central nervous system to the enteric immune system and the gut microbiota. To cover all agents that

Received: June 1, 2015 Revised: None Accepted: June 23, 2015

(c) This is an Open Access article distributed under the terms of the Creative Commons Attribution Non-Commercial License (http://creativecommons. org/licenses/by-nc/4.0) which permits unrestricted non-commercial use, distribution, and reproduction in any medium, provided the original work is properly cited.

*Correspondence: Eamonn M M Quigley, MD, FRCP, FACP, FACG, FRCPI Division of Gastroenterology and Hepatology, Houston Methodist Hospital, 6550 Fannin St, SM 1001, Houston, Texas 77030, USA

Financial support: None. Tel: +1-713-441-0853, Fax: +1-713-797-9595, E-mail: equigley@tmhs.org

Conflicts of interest: None.

ORCID: Eamonn M M Quigley, http://orcid.org/0000-0003-4151-7180. 
have been developed, or are in development, to address any one or a combination of these factors is beyond the scope of this review and the reader is referred to an elegant and recent review by Camilleri $^{1}$ for a more comprehensive overview of this area. Instead, this review will focus on those strategies which have been developed to specifically address gastrointestinal motility and its stimulation, in particular.

\section{The Prokinetic Approach: Challenges}

Before enumerating the list of agents that have effects on motility and discussing their relative merits and shortcomings, it is important that some challenges intrinsic to this class of compounds be explored. Anyone who has worked in this area over the past several decades will have borne witness to the many trials and infrequent tribulations that have been associated with this area. So what are the problems?

\section{Is the Simple Stimulation of Gut Motility a Valid Target?}

The focus of past research efforts on the synthesis and testing of compounds that mimicked the major excitatory neurotransmitters of the gastrointestinal tract (such as acetylcholine) was based on the assumption that reduced or absent motor activity was fundamental to the pathophysiology and the genesis of symptoms in a number of apparently intractable disorders. ${ }^{2}$ Gastroparesis serves as an excellent example of the shortcomings of this approach. A primary target for many new prokinetic agents, gastroparesis proved to be a most frustrating testing ground for novel compounds as little correlation could be found between the accelerating effects of various agents on gastric emptying and symptom responses. It is now apparent that factors other than the one that we can most readily measure, gastric emptying, must be involved in the generation of symptoms in affected individuals. Similarly, constipation is now viewed as more than just infrequent bowel movements and a simple prokinetic action may not address the constellation of symptoms that are now included under the umbrella of chronic idiopathic (or functional) constipation.

\section{Target Disorders Are Poorly Defined}

In contrast to what might be termed the "classical" motility disorders, such as achalasia, scleroderma, or Hirschsprung's disease where pathophysiology is well understood and therapeutic approaches can be accordingly developed, many of the disorders that crept under the flysheet and gained access to the tent that was "motility" (such as functional dyspepsia [FD] and IBS) were defined on the basis of symptom aggregations alone. As a consequence, it is undoubted that these entities contain heterogeneous patient populations and are likely to encompass a number of pathophysiological processes. ${ }^{3}$ These were not, despite their frequency in the general population and resultant attractiveness to pharmaceutical companies, good testing grounds for drugs that had a single primary effect: the stimulation of motility. Pharmaceutical companies were attracted nevertheless by the apparently vast size of the "functional" market and pursued the development of prokinetic agents. Not surprisingly, functional gastrointestinal disorders have proven to be a virtual minefield for such drugs.

\section{Non-selective Drugs Will Have Side Effects}

We have learned repeatedly of the problems that seem to be inevitably encountered when non-selective agents are used to promote gut motility. Firstly, "dirty" drugs that interact with more than one receptor in the gastrointestinal tract may induce a plethora of effects some desirable and others undesirable and, perhaps, even contrary to the expected primary action. Secondly, effects on other receptors will inevitably lead to unwanted side effects. Thus the cholinergics could not be tolerated because of bladder spasms and cisapride was withdrawn because of cardiac toxicity. In the latter example the effect was an unexpected one; an interaction with the Human Ether-a-go-go-Related Gene (hERG) channel led to the occurrence of hERG channel-mediated cardiac arrhythmias, such as Torsades de Pointes and ventricular tachycardia. ${ }^{4}$ Though many of these adverse events were related to preexisting cardiac disease or the co-administration of cisapride with drugs that either had similar effects on cardiac electrophysiology (prolongation of the Q-T interval) or that altered the metabolism of cisapride, a few occurred in individuals who did not have obvious risk factors and led to the withdrawal of the drug world-wide. All new compounds are now tested for Q-T effects. ${ }^{5}$ More recently and, perhaps more troublingly, toxicities have appeared which are more difficult to explain, such as the rare instances of cardiovascular adverse events that led to the demise of tegaserod. ${ }^{5}$ For all of these reasons, the goal of modern drug development in this area has been to attempt the highest degree possible of receptor and tissue selectivity. ${ }^{6}$

\section{Regulatory Hurdles}

Chastened by their experiences with cisapride and tegaserod (as well as with other drugs targeted at IBS such as alosetron and 
cilansetron), regulatory agencies have raised the bar significantly when it comes to the approval of prokinetic and related drugs. On the assumption that the target disorders are not life-threatening, regulatory agencies have adopted a virtual zero tolerance stance in relation to serious adverse events for this drug category. While this approach may emphasize "safety first," it has served to stifle drug development in an area that is populated by some, albeit a minority, individuals with severely disabling disorders, such as gastroparesis, pseudoobstruction and severe IBS.

\section{Available Compounds}

\section{Cholinergic Agonists}

Cholinergic agonists, the original promotility agents, stimulate muscarinic M2-type receptors on the smooth muscle cell. Recently, anticholinesterases have also been used to a limited extent. Evidence for their effectiveness in motility disorders is inconsistent. Although bethanechol had been used for reflux and gastroparesis, ${ }^{8}$ its use for these indications has virtually disappeared with the introduction of newer agents. Neostigmine and pyridostigmine continue to be employed in clinical practice for Ogilvie's syndrome and pseudo-obstruction, respectively.

\section{Dopamine Antagonists}

Until recently, the most widely used prokinetic agent was metoclopramide, a dopamine antagonist with central and peripheral effects. Domperidone, a dopamine antagonist that does not cross the blood-brain barrier and operates primarily through peripheral $\left(\mathrm{DA}_{2}\right)$ receptors, is available for use throughout Europe, as well as in Canada, Mexico, and South America but not in the United States. ${ }^{9,10}$ The efficacy of metoclopramide in motility disorders has been far from consistent, and its long-term use has been complicated by a trend toward tolerance and a significant incidence of CNS side effects. ${ }^{11} \mathrm{Up}$ to $25 \%$ of patients may experience side effects, the most troubling of which are extrapyramidal reactions. ${ }^{12}$ Some of these may not be reversible and led to the attachment of a "black box" to the metoclopramide package insert in the US. Both metoclopramide and domperidone may elevate serum prolactin levels and cause gynecomastia and galactorrhea. These dopamine antagonists are primarily effective in the foregut and have shown efficacy in gastroparesis, gastroesophageal reflux disease, and dyspepsia. ${ }^{13,14}$ An important advantage of these agents is that both also act as central antiemetics, by virtue of the fact that the vomiting center lies on the blood side of the blood- brain barrier. Furthermore, metoclopramide is available for both oral and parenteral use and in a generic form. Levosulpiride, a DA2 antagonist in development, has been shown to accelerate gastric emptying in diabetics and to improve glycemic control over a 6-month period. ${ }^{15}$ Levosulpiride also appeared effective in dyspepsia, ${ }^{16,17}$ perhaps via acceleration of gastric emptying. ${ }^{17}$

\section{Serotonergic Agonists}

In the substituted benzamide group of prokinetics, cisapride was the prototype. It facilitated acetylcholine release from myenteric neurons through a 5-hydroxytryptamine type $4\left(5-\mathrm{HT}_{4}\right)$ receptor-mediated effect. Cisapride was shown to promote esophageal peristalsis, augment lower esophageal sphincter pressure and accelerate gastric emptying. In clinical trials cisapride demonstrated benefit (not always consistent) in both the short- and long-term therapy of gastroparesis and dyspepsia. ${ }^{18,19}$ However, all of this promise came to naught when reports of serious cardiac arrhythmias, related to QT interval prolongation ${ }^{20,21}$ began to appear.

The withdrawal of cisapride spurred interest in the development of alternative $5-\mathrm{HT}_{4}$ agonists. Of these, tegaserod (an aminoguanidine indole and not a substituted benzamide), showed an ability to accelerate intestinal transit, ${ }^{22}$ reduce esophageal acid exposure, ${ }^{23}$ and promote gastric accommodation ${ }^{24}$ and was subsequently approved for the management of constipation-predominant IBS. Rare cardiovascular side effects led to its ultimate withdrawal. $^{25}$

After a gap of some years, interest has recently been reawakened in $5-\mathrm{HT}_{4}$ agonists and one, prucalopride is now available in several countries. In contrast to cisapride and tegaserod, prucalopride (a benzofuran) is a high affinity, highly selective $5-\mathrm{HT}_{4}$ agonist that has very low affinity for other 5-HT receptors and for the hERG-K ${ }^{+}$cardiac channels. ${ }^{26-28}$ Its high affinity for the $5-\mathrm{HT}_{4}$ receptor confers greater efficacy for prucalopride while low affinity for the $\mathrm{hERG}-\mathrm{K}^{+}$channel explains why it has not been shown to be arrhythmogenic ${ }^{29}$; together they confer a major therapeutic advantage for prucalopride over cisapride. As a prokinetic agent prucalopride promotes colonic motility and transit.

Prucalopride has been studied in three large ( $>500$ patients), multi-center, double blind, placebo-controlled trials; these that showed that prucalopride significantly improved bowel function, reduced constipation-related symptoms, improved patient satisfaction and constipation-related quality of life. ${ }^{30-32}$ The most common adverse effects reported from these trials included head- 
ache $(25-30 \%$ in prucalopride vs $12-17 \%$ in placebo), nausea (12-24\% vs $8-14 \%)$, abdominal pain or cramps (16-23\% vs $11-19 \%)$ and diarrhea (12-19\% vs 3-5\%). Prucalopride is currently approved in a number of countries for treatment of chronic constipation in women who failed laxative treatment and has been shown to be effective in this sub-population. ${ }^{33}$ The current recommended dose is $2 \mathrm{mg}$ once daily in oral tablet form. It has been used safely in the elderly where a lower dose of $1 \mathrm{mg}$ per day is recommended. Velusetrag is another selective $5-\mathrm{HT}_{4}$ agonist that stimulates colonic motility and transit ${ }^{34}$ and in a 4-week phase II dose-ranging study has been shown to increase spontaneous bowel movements in chronic constipation ${ }^{35}$; results of phase III studies are awaited. Naronapride has also been studied in a single randomized controlled trial and shown to be effective in chronic constipation. ${ }^{36}$ For all of these highly selective $5-\mathrm{HT}_{4}$ agonists, side effects were generally minor with headache being the most frequent problem. ${ }^{37}$

Mosapride is a benzamide derivative (4-amino-5-chloro-2thoxy-N-\{[4-(4-fluorobenzyl)-2-morpholinyl] methyl $\}$ benzamide citrate) that acts as a selective $5-\mathrm{HT}_{4}$ agonist in the gastrointestinal tract and does not appear to have any significant affinity for $5-\mathrm{HT}_{1}, 5-\mathrm{HT}_{2}$, dopamine $\mathrm{D}_{2}$, or adrenergic (alpha 1 or alpha 2) receptors. ${ }^{38}$

Mosapride is available as a prokinetic agent in a number of Asian countries. Several studies have been performed to assess the efficacy of mosapride for the treatment of FD. The largest prospective study was a double-blind, placebo-controlled multi-national study in FD comparing 3 doses of mosapride $(5 \mathrm{mg}$ b.i.d. vs $10 \mathrm{mg}$ b.i.d. vs $7.5 \mathrm{mg}$ t.i.d.) to placebo during a 6-week treatment period. ${ }^{39}$ In the intention-to-treat analysis of $566 \mathrm{pa-}$ tients there was no difference in dyspeptic symptoms between placebo and any of the 3 mosapride treatment groups. All other studies in FD have been small with no placebo group, and often limited by the lack of a validated screening instrument. ${ }^{40-43}$ Two small, open-label studies have demonstrated limited efficacy of mosapride in patients with diabetic gastropathy. ${ }^{44,45}$ The efficacy of mosapride for the treatment of constipation was assessed in an open-label study of 14 patients with Parkinson's disease (mean age $=67,10 \mathrm{men})$. Mosapride $(15 \mathrm{mg} /$ day $)$ objectively improved stool frequency and subjectively improved stool evacuation in 13 of 14 patients, and shortened total colonic transit time $(P<0.05) .{ }^{46}$ In contrast to cisapride, mosapride does not appear to have any significant effect on $\mathrm{K}^{+}$channels and studies published to date demonstrate that mosapride is safe without any significant cardiovascular effects.

\section{Macrolides}

It has been known for some time that erythromycin is a motilin agonist. Evidence for therapeutic efficacy in gastroparesis is more recent. In a comprehensive review, Camilleri ${ }^{47}$ concluded that erythromycin is most useful in acute gastroparesis and recommended a regimen that begins with intravenous erythromycin lactobionate ( $3 \mathrm{mg} / \mathrm{kg}$ every 8 hours) and continues with oral administration ( $250 \mathrm{mg}$ three times a day) for 5 to 7 days. ${ }^{47}$ Efficacy with long-term oral administration has been less obvious ${ }^{48,49}$ and may be complicated by the risks associated with long-term antibiotic use ${ }^{49}$; in general, data remains scanty. ${ }^{50}$ There is also evidence that the salutory response to erythromycin may be blunted by hyperglycemia. ${ }^{51,52}$ Other modes of administration are under evaluation. ${ }^{53,54}$ Azithromycin, which has better oral biovailability than erythromycin, seems to have comparable effects. ${ }^{55}$ It also suffers, of course from being an antibiotic and the search for a non-antibiotic but prokinetic macrolide continues. ${ }^{56}$

\section{Other Agents}

Itopride is a dopamine D2 antagonist with prokinetic effects but devoid of central nervous system or cardiovascular side effects and causes minimal elevation of prolactin levels. ${ }^{57}$ Though a recent meta-analysis concluded that it has benefits in $\mathrm{FD},{ }^{57}$ the major phase III studies were negative. ${ }^{58}$ It is available in some countries. Several different approaches are currently under development and are listed in Table.

Table. New Therapeutic Targets and/or Prokinetic Agents (Adapted from Shin et $\mathrm{al}^{37}$ )

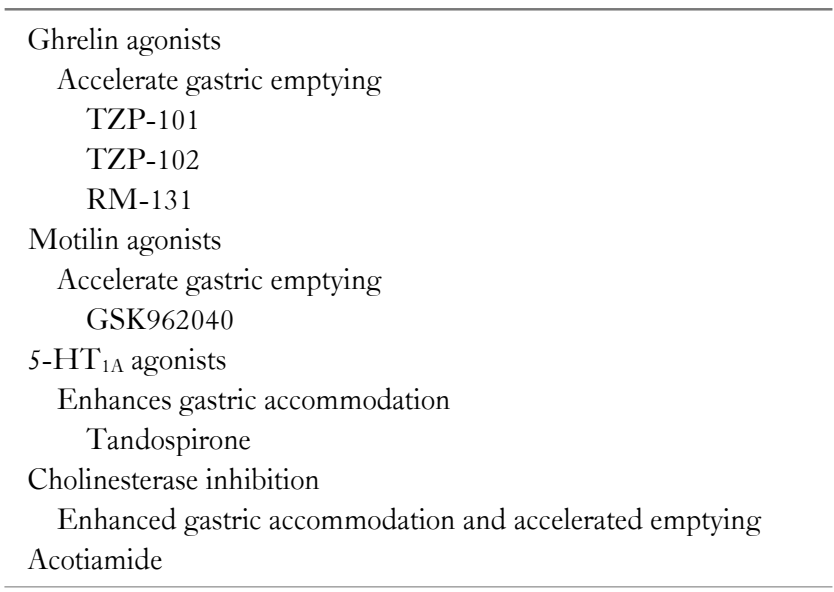

5 - $\mathrm{HT}_{1 \mathrm{~A}}, 5$-hydroxytryptamine type $1 \mathrm{~A}$ receptor. 


\section{Future Directions}

These have been difficult times for traditional prokinetics. In the past, their results were often disappointing and complicated by unacceptable adverse events. We must learn from these experiences and select patients that are likely to truly benefit from the prokinetic approach and drugs that are not only effective agonists but highly selective for receptor, tissue and therapeutic target.

Though the role of simple prokinesia in the management of motility and functional disorders may have suffered from gross oversimplification, there is a need in clinical practice for agents that stimulate motility and for further work on agents that affect other physiological processes relevant to symptom pathogenesis in these disorders.

In the management of the more complex and multifactorial disorders, while the search for highly specific agent is logical given the problems that have arisen as a consequence of unexpected adverse events, there may be some advantages to a "dirty" drug. For example, a drug with 5- $\mathrm{HT}_{4}$ agonist (promotility) and 5- $\mathrm{HT}_{3}$ antagonist (visceral analgesic) would seem attractive in IBS. In another arena, the unexpected but apparent anti-nociceptive effects of the pro-secretory agent, linaclotide, may contribute to its benefits on pain in constipation-predominant IBS $^{59}$ and the neuroprotective effects of prucalopride ${ }^{60}$ may have significant implications for the long-term outlook of enteric neuropathic disorders.

\section{References}

1. Camilleri M. Pharmacological agents currently in clinical trials for disorders in neurogastroenterology. J Clin Invest 2013;123:41114120 .

2. Quigley EM. The clinical pharmacology of motility disorders: the perils (and pearls) of prokinesia. Gastroenterology 1994;106:11121114.

3. Quigley EM. The "Con" case. The Rome process and functional gastrointestinal disorders: the barbarians are at the gate! Neurogastroenterol Motil 2007;19:793-797.

4. Quigley EM. Cisapride. What can we learn from the rise and fall of a prokinetic? J Dig Dis 2011;12:147-156.

5. Tack J, Camilleri M, Chang L, et al. Systematic review: cardiovascular safety profile of $5 \mathrm{HT}_{4}$ agonists developed for gastrointestinal disorders. Aliment Pharmacol Ther 2012;35:745-767.

6. Mozaffari S, Didari T, Nikfar S, Abdollahi M. Phase II drugs under clinical investigation for the treatment of chronic constipation. Expert Opin Investig Drugs 2014;23:1485-1497.

7. Quigley EM. Why do we have so few effective drugs for irritable bowel syndrome? A European perspective. Nat Clin Pract Gastroen- terol Hepatol 2005;2:436-437.

8. Malagelada JR, Rees WD, Mazzotta LJ, Go VL. Gastric motor abnormalities in diabetic and post-vagotomy gastroparesis: effect of metoclopramide and bethanechol. Gastroenterology 1980;78:286-293.

9. Barone JA. Domperidone: a peripherally acting dopamine 2-receptor antagonist. Ann Pharmacother1999;33:429-440.

10. Tonini M, Cipollina L, Poluzzi E, Crema F, Corazza GR, De Ponti F. Review article: clinical implications of enteric and central D2 receptor blockade by antidopaminergic gastrointestinal prokinetics. Aliment Pharmaol Ther 2004;19: 379-390.

11. Lata PF, Pigarelli DL. Chronic metoclopramide therapy for diabetic gastroparesis. Ann Pharmacother 2003;37:122-126.

12. Ganzini L, Casey DE, Haffman WF, McCall AL.The prevalence of metoclopramide-induced tardive dyskinesia and acute extrapyramidal movements. Arch Intern Med 1993;153:1469-1475.

13. Horowitz M, Harding PE, Chatterton BE, Collins PJ, Shearman DJ. Acute and chronic effects of domperidone on gastric emptying in diabetic autonomic neuropathy. Dig Dis Sci 1985;30:1-9.

14. Kranzese A, Borrelli O, Corrado G, et al. Domperidone is more effective than cisapride in children with diabetic gastroparesis. Aliment Pharmacol Ther 2002;16:951-957.

15. Melga P, Mansi C, Ciuchi E, Giusti R, Sciaba L, Prando R. Chronic administration of levosulpiride and glycemic control in IDDM patients with gastroparesis. Diabetes Care 1997;20:55-58.

16. Corazza GR, Biagi F, Albano $\mathrm{O}$, et al. Levosulpiride in functional dyspepsia: a multicentric, double-blind, controlled trial. Ital J Gastroenterol 1996;28:317-323.

17. Mansi C, Borro P, Giacomini M, et al. Comparative effects of levosulpiride and cisapride on gastric emptying and symptoms in patients with functional dyspepsia and gastroparesis. Aliment Pharmacol Ther 2000;14:561-569.

18. Camilleri M, Malagelada JR, Abell TL, Brown ML, Hench V, Zinsmeister AR. Effect of six weeks of treatment with cisapride in gastroparesis and intestinal pseudo-obstruction. Gastroenterology 1989;96:704-712.

19. Abell TL, Camilleri M, DiMagno EP, Hench VS, Zinsmeister AR, Malagelada JR. Long-term efficacy of oral cisapride in symptomatic upper gut dysmotility. Dig Dis Sci 1991;36:616-620.

20. Vitola J, Vukanovic J, Roden DM. Cisapride-induced torsades de pointes. J Cardiovasc Electrophysiol 1998;9:1109-1113.

21. Wang SH, Lin CY, Huang TY, Wu WS, Chen CC, Tsai SH.QT interval effects of cisapride in the clinical setting. Int J Cardiol 2001; 80:179-183.

22. Prather CM, Camilleri M, Zimsmeister AR, McKinzie S, Thomforde G.Tegaserod accelerates orocecal transit in patients with constipation-predominant irritable bowel syndrome. Gastroenterology 2000;118:463-468.

23. Kahrilas PJ, Quigley EM, Castell DO, Spechler SJ. The effects of tegaserod (HFT 919) on oesophageal acid exposure in gastro-oesophageal reflux disease. Aliment Pharmacol Ther 2000;14:1503-1509.

24. Tack J, Vos R, Janssens J, Salter J, Jauffret S, Vandeplassche G. Influence of tegaserod on proximal gastric tone and on the perception of gastric distension. Aliment Pharmacol Ther 2003;18:1031-1037.

25. Busti AJ, Murillo JR Jr, Cryer B. Tegaserod-induced myocardial infarction: case report and hypothesis. Pharmacotherapy 2004;24:526531. 
26. Quigley EM. Prucalopride: safety, efficacy and potential applications. Therap Adv Gastroenterol 2012;5:23-30.

27. Sanger GJ, Quigley EM. Constipation, IBS and the $5-\mathrm{HT}_{4}$ receptor: what role for prucalopride? Clin Med Insights Gastroenterology 2010;3:21-33.

28. Potet F, Bouyssou T, Escande D, Baró I. Gastrointestinal prokinetic drugs have different affinity for the human cardiac human ether-agogo $\mathrm{K}^{+}$channel. J Pharmacol Exp Ther 2001;299:1007-1012.

29. Mendzelevski B, Ausma J, Chanter DO, et al. Assessment of the cardiac safety of prucalopride in healthy volunteers: a randomized, double-blind, placebo- and positive-controlled thorough QT study. Br J Clin Pharmacol 2012;73:203-209.

30. Camilleri M, Kerstens R, Rykx A, Vandeplassche L. A placebo-controlled trial of prucalopride for severe chronic constipation. N Engl J Med 2008;358:2344-2354.

31. Tack J, van Outryve M, Beyens G, Kerstens R, Vandeplassche L. Prucalopride (Resolor) in the treatment of severe chronic constipation in patients dissatisfied with laxatives. Gut 2009;58:357-365.

32. Quigley EM, Vandeplassche L, Kerstens R, Ausma J. Clinical trial: the efficacy, impact on quality of life, and safety and tolerability of prucalopride in severe chronic constipation--a 12-week, randomized, double-blind, placebo-controlled study. Aliment Pharmacol Ther 2009;29:315-328.

33. Tack J, Quigley E, Camilleri M, Vandeplassche L, Kerstens R. Efficacy and safety of oral prucalopride in women with chronic constipation in whom laxatives have failed: an integrated analysis. United European Gastroenterol J 2013;1:48-59.

34. Manini ML, Camilleri M, Goldberg M, et al. Effects of Velusetrag (TD-5108) on gastrointestinal transit and bowel function in health and pharmacokinetics in health and constipation. Neurogastroenterol Motil 2010;22:42-49, e7-e8.

35. Goldberg M, Li YP, Johanson JF, et al. Clinical trial: the efficacy and tolerability of velusetrag, a selective $5-\mathrm{HT}_{4}$ agonist with high intrinsic activity, in chronic idiopathic constipation - a 4-week, randomized, double-blind, placebo-controlled, dose-response study. Aliment Pharmacol Ther 2010;32:1102-1112.

36. Palme M, Milner PG, Ellis DJ, Marmon T, Canafax DM. A novel gastrointestinal prokinetic, ATI-7505, increased spontaneous bowel movements (SBMs) in a phase II, randomized, placebo-controlled trial of patients with chronic idiopathic constipation (CIC). Gastroenterology 2010;138:S128-S129.

37. Shin A, Camilleri M, Kolar G, Erwin P, West CP, Murad MH. Systematic review with meta-analysis: highly selective $5-\mathrm{HT}_{4}$ agonists (prucalopride, velusetrag or naronapride) in chronic constipation. Aliment Pharmacol Ther 2014;39:239-253

38. Yoshida N, Omoya H, Oka M, Furukawa K, Ito T, Karasawa T. AS-4370, a novel gastrokinetic agent free of dopamine D2 receptor antagonist properties. Arch Int Pharmacodyn Ther 1989;300:51-67.

39. Hallerback BI, Bommelaer G, Bredberg E, et al. Dose finding study of mosapride in functional dyspepsia: a placebo-controlled, randomized study. Aliment Pharmacol Ther 2002;16:959-967.

40. Amarapurkar DN, Rane P. Randomised, double-blind, comparative study to evaluate the efficacy and safety of ganaton (itopride hydrochloride) and mosapride citrate in the management of functional dyspepsia. J Indian Med Assoc 2004;102:735-737.

41. Otaka M, Jin M, Odashima M, et al. New strategy of therapy for functional dyspepsia using famotidine, mosapride and amitriptyline. Aliment Pharmacol Ther 2005;21(suppl 2):42-46.

42. Kinoshita Y, Hashimoto T, Kawamura A, et al. Effects of famotidine, mosapride and tandospirone for treatment of functional dyspepsia. Aliment Pharmacol Ther 2005;21(suppl 2):37-41.

43. Seno $H$, Nakase $H$, Chiba $T$. Usefulness of famotidine in functional dyspepsia patient treatment: comparison among prokinetic, acid suppression and antianxiety therapies. Aliment Pharmacol Ther 2005; 21(suppl 2):32-36.

44. Koshiyama H, Shimono D, Wada Y, Nakamura Y. Improvement of glycemic control after treatment with mosapride for diabetic gastropathy. Diabetes Care 2000;23:1198-1199.

45. Asakawa H, Hayashi I, Fukui T, Tokunaga K. Effect of mosapride on glycemic control and gastric emptying in type 2 diabetes mellitus patients with gastropathy. Diabetes Res Clin Pract 2003;61:175-182.

46. Liu Z, Sakakibara R, Odaka T, et al. Mosapride citrate, a novel 5- $\mathrm{HT}_{4}$ agonist and partial 5- $\mathrm{HT}_{3}$ antagonist, ameliorates constipation in parkinsonian patients. Mov Disord 2005;20:680-686.

47. Camilleri M. The current role of erythromycin in the clinical management of gastric emptying disorders. Am J Gastroenterol 1993; 88:169-171.

48. Dhir R, Richter JE. Erythromycin in the short-and long-term control of dyspepsia symptoms in patients with gastroparesis. J Clin Gastroenterol 2004:38:237-242

49. Richards RD, Davenport K, McCallum RW. The treatment of idiopathic and diabetic gastroparesis with acute intravenous and chronic oral erythromycin. Am J Gastroenterol 1993;88:203-207.

50. Maganti K, Onyemere K, Jones MP. Oral erythromycin and symptomatic relief of gastroparesis: a systematic review. Am J Gastroenterol 2003;98:259-263.

51. Jones KL, Berry M, Kong MF, Kwiatek MA, Samsom M, Horowitz M. Hyperglycemia attenuates the gastrokinetic effect of erythromycin and affects the perception of post-prandial hunger in normal subjects. Diabetes Care 1999;22:339-344.

52. Petrakis IE, Vrachassotakis N, Sciacca V, Vassilakis SI, Chalkiadakis G. Hyperglycemia attenuates erythromycin-induced acceleration of solid-phase gastric emptying in idiopathic and diabetic gastroparesis. Scand J Gastroenterol 1999;34:396-403.

53. Brand RM, Lof J, Quigley EM. Transdermal delivery of erythromcyin lactobionate -implications for the therapy of gastroparesis. Aliment Pharmacol Ther 1997;11:589-592.

54. DiBiase JK, Quigley EM. Efficacy of long-term intravenous erythromycin in the treatment of severe gastroparesis: one center's experience. J Clin Gastroenterol 1999;28:131-134.

55. Larson JM, Tavakkoli A, Drane WE, Toskes PP, Moshiree B. Advantages of azithromycin over erythromycin in improving the gastric emptying half-time in adult patients with gastroparesis. J Neurogastroenterol Motil 2010;16:407-413.

56. Tack J, Peeters T. What comes after macrolides and other motilin stimulants? Gut 2001;49:317-318.

57. Huang X, Lv B, Zhang S, Fan YH, Meng LN. Itopride therapy for functional dyspepsia: a meta-analysis. World J Gastroenterol 2012; 18:7371-7377.

58. Talley NJ, Tack J, Ptak T, Gupta R, Giguère M. Itopride in functional dyspepsia: results of two phase III multicentre, randomised, double-blind, placebo-controlled trials. Gut 2008;57:740-746. 
59. Castro J, Harrington AM, Hughes PA, et al. Linaclotide inhibits colonic nociceptors and relieves abdominal pain via guanylate cyclase-C and extracellular cyclic guanosine 3',5'-monophosphate. Gastroenterology 2013;145:1334-1346, e1-e11.
60. Bianco F, Bonora E, Vargiolu M, et al. Enteric neuroprotection in human neurons: effects mediated by prucalopride, a serotonergic full 5- $\mathrm{HT}_{4}$ agonist [abstract]. United European Gastroenterol J 2014;2 (suppl 1). 